ORIGINAL PROF-2114

\title{
HYPERTENSIVE PATIENTS;
}

Frequency of diabetes mellitus and impaired fasting glucose levels

\section{Dr. Shahana Arshi, Dr. Fakhra Naheed, Dr. Mazhar Badshah, Dr. Farrah Naz, Dr Kamran Sardar}

ABSTRACT.....Objective: To see the frequency of diabetes mellitus and impaired fasting glucose levels in hypertensive patients. Design: Descriptive study. Place of Study: OPD / Filter clinic. Pakistan Institute of Medical Sciences. Islamabad. Patients and Methods: This study was carried out on 116 hypertensive patients during the period from August to September '2008. Out of 116 patients, 64 were females and 52 were males with age group between 20 to 70 years. Secondary causes are ruled out on the basis of history and physical examination. Blood samples were sent to PIMS laboratory for fasting glucose. Data and results were analyzed in SPSS. Results: According to this study, out of 116 patients, there were 18 patients who had diabetes mellitus while 33 had hypertension with impaired fasting glucose tolerance which is statistically significant. The females as compared to males were increased in number who had both diabetes mellitus and impaired fasting glucose. According to age diabetes mellitus increased in age groups between 41-50 and 61-70 years while impaired fasting glucose were increased in age group between 31-60 yrs. The results indicate that impaired fasting glucose is present in significant number of hypertensive patients. Conclusions: Hypertension is associated with diabetes mellitus and impaired fasting glucose.

Key words: Hypertension, Diabetes mellitus, impaired fasting glucose.

Article Citation

Arshi S, Naheed F, Badshah M, Naz F, Sardar K. Hypertensive Patients; Frequency of diabetes mellitus and impaired fasting glucose levels. Professional Med J 2013;20(3): 341-347.

\section{INTRODUCTION}

Hypertension (systolic pressure $\geq 140 \mathrm{~mm} \mathrm{Hg}$ or diastolic pressure $\geq 90 \mathrm{~mm} \mathrm{Hg}$ ) is present in one out of four adults in the United States. Hypertension is a risk factor for stroke, myocardial infarction, renal failure, congestive heart failure, progressive atherosclerosis, and dementia. Systolic pressure is a stronger predictor of cardiovascular events than is diastolic pressure, and isolated systolic hypertension which is common among older persons, is particularly hazardous. Treatment of hypertension reduces the risk of stroke, coronary artery disease, and congestive heart failure, as well as overall cardiovascular morbidity and mortality from cardiovascular causes ${ }^{1}$.

Cardiovascular diseases (CVD) are a major cause of death in developed countries, and are also on the rise in developing countries ${ }^{2,3}$. According to global burden of disease pattern, South Asia is facing the burden of non-communicable diseases ${ }^{4}$. Our country being a developing country is encountering a double burden of disease as part of the epidemiological transition. This will lead to increased prevalence of hypertension as a result of increased life expectancy and rapid urbanization. High blood pressure is one of the common cardiovascular risk factors in Pakistan affecting one in three individuals over the age of 45 years ${ }^{5}$. The National Health Survey of Pakistan (NHSP1990-94) shows that 5.5 million men and 5.3 million women were hypertensives ${ }^{6}$.

Hypertension is a multifactor disorder but any individual risk factor can contribute to overall increase in blood pressure ${ }^{7}$. Hypertension frequently co exists with diabetes, there is an increased prevalence of hypertension among diabetic patients ${ }^{8}$ but there is also high propensity among hypertensive patients to develop type-2 diabetes ${ }^{9}$. Persons with isolated IFG show an approximately $25 \%$ decrease in insulin sensitivity, and individuals with combined IFG and IGT show a decrease of approximately $80 \%$ in insulin sensitivity compared with persons with fasting glucose concentrations within reference intervals (10).

We wished to explore this feature in hypertensive 
patients who present in our clinical environment.

\section{MATERIAL AND METHODS}

This study was conducted on 116 hypertensive patients from August to September 2008 at OPD Filter Clinic, Pakistan Institute of Medical Sciences. Islamabad.

\section{INCLUSION CRITERIA}

Eligible patients were in between age of 20 to 70 years of age. Random selection of 116 patients were taken. After informed consent, history was taken, physical examination were carried out including blood pressure. All patients were known cases of hypertension and they had not checked their glucose levels before.

\section{EXCLUSION CRITERIA}

Patients who are known diabetics were excluded. Secondary causes of HTN should be considered in patients responding poorly to medications, (particularly those with previously well-controlled HTN); in patients with stage 3 HTN; and those with sudden onset HTN. Many potential causes are found for secondary HTN. Secondary causes were ruled out on the basis of history and physical examination.

Arterial pressure imeasured via a sphygmomanometer, which historically used the height of a column of mercury to reflect the circulating pressure.BP values are generally reported in millimetres of mercury ( $\mathrm{mmHg}$ ).

The following US classification of blood pressure applies to adults aging 18 and older. It is based on the average of seated BP readings that were properly measured during 2 or more office visits.

Blood samples were sent to PIMS laboratory for fasting glucose. (After $8 \mathrm{hr}$ of fast) WHO criteria were used for the diagnosis of diabetes mellitus and impaired fasting glucose levels.

\section{WHO Criteria}

Diabetes mellitus $>126 \mathrm{mg} / \mathrm{dl}$ Impaired fasting glucose $110-126 \mathrm{mg} / \mathrm{dl}$

Patients showed Fasting glucose $>126 \mathrm{mg} / \mathrm{dl}$ checked for random blood sample to check its value and for the diagnosis of diabetes mellitus. Data analyzed according to systolic blood pressure, diastolic blood pressure age and sex. Data and results were analyzed in SPSS.

\begin{tabular}{|l|c|c|}
\hline Category & Systolic, mmHG & Diastolic, mmHG \\
\hline Hypotension & $<90$ & $<60$ \\
\hline Desirable & $\mathbf{9 0 - 1 1 9}$ & $\mathbf{6 0}-\mathbf{7 9}$ \\
\hline Prehypertension & $120-139$ & or $80-89$ \\
\hline Stage 1 Hypertension & $140-159$ & or $90-99$ \\
\hline Stage 2 Hypertension & $160-179$ & or $100-109$ \\
\hline Hypertensive Crisis & $\geq 180$ & or $\geq 120$ \\
\hline \multicolumn{2}{|c|}{ Classification of blood pressure for adults } \\
\hline
\end{tabular}

\section{RESULTS}

A total number of 116 patients were included. There were $64(55.1 \%)$ females and 52 (44.8\%) males.

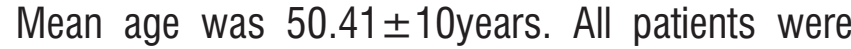
hypertensive. Main number of patients (45) 38.7\% were in age group 41-50 years. Females are increased in number in both diabetes mellitus and impaired fasting glucose. (Table-I)

Out of 116 patients, 65 (56\%) hypertensive patients had normal blood sugar levels, 33 (28.4\%) hypertensive patients had impaired fasting glucose levels and 18 (15.5\%) hypertensive patients found to be newly diagnosed diabetes mellitus.

In patients with impaired fasting glucose, 11(33.3) patients were in age group 31-40 years. In patients who are newly diagnosed diabetes mellitus $9(50 \%)$ patients were in 41-50 years. This also describes that 
diabetes mellitus increased in age groups between 41 50 and 61-70 years while impaired fasting glucose were increased in age group between 31-60 yrs. (Table-II). Impaired fasting glucose increased at younger age, so it can be controlled by diet, exercise and weight reduction.

The systolic and diastolic blood pressure in newly diagnosed diabetes mellitus and impaired fasting glucose were also shown some differences. In newly diagnosed diabetes mellitus 10 (55\%) patients had systolic blood pressure ranges in between 160-180 mmHg. (Table-III). Similarly 10 (55.5\%) patients had diastolic blood pressure ranges $91-100 \mathrm{mmHg}$. (Table-IV)

In impaired fasting glucose, two ranges of systolic blood pressure were seen. These were 141-150 and $161-170 \mathrm{mmHg}$. Both groups had equal number i.e., $10(30.3 \%)$ (Table-V). Same was the case with diastolic blood pressure. The diastolic blood pressure two ranges were $91-100$ and $101-110 \mathrm{mmHg}$ and number of patients were 15 (44.5). (Table-VI). DISCUSSION

\begin{tabular}{|c|c|c|}
\hline Age (yrs) & Female (64) & Male (52) \\
\hline $20-30$ & 2 & - \\
\hline $31-40$ & 11 & 14 \\
\hline $41-50$ & 26 & 19 \\
\hline $51-60$ & 18 & 10 \\
\hline $61-70$ & 7 & 9 \\
\hline
\end{tabular}

\begin{tabular}{|c|c|c|c|c|c|c|}
\hline \multirow{2}{*}{ Age (yrs) } & \multicolumn{2}{|c|}{$\begin{array}{c}\text { Diabetes Mellitus } \\
\mathbf{1 8}\end{array}$} & \multicolumn{2}{c|}{$\begin{array}{c}\text { Impaired Fasting Glucose } \\
\text { (33) }\end{array}$} & \multicolumn{2}{c|}{$\begin{array}{c}\text { Normal } \\
\text { (65) }\end{array}$} \\
\cline { 2 - 8 } & Female (12) & Male (6) & Female (18) & Male (15) & Female (34) & Male (31) \\
\hline $20-30$ & - & - & - & - & 2 & - \\
\hline $31-40$ & 2 & 1 & 3 & 8 & 6 & 5 \\
\hline $41-50$ & 5 & 4 & 8 & 1 & 13 & 14 \\
\hline $51-60$ & 2 & - & 6 & 4 & 10 & 6 \\
\hline $61-70$ & 3 & 1 & 1 & 2 & 3 & 6 \\
\hline
\end{tabular}

\begin{tabular}{|c|c|c|c|c|c|c|c|c|c|c|c|c|c|c|}
\hline \multirow{3}{*}{ Age (yrs) } & \multicolumn{14}{|c|}{ Systolic B.P (18) } \\
\hline & \multicolumn{2}{|c|}{$120-130$ (2) } & \multicolumn{2}{|c|}{$131-140$ (1) } & \multicolumn{2}{|c|}{$141-150(4)$} & \multicolumn{2}{|c|}{$151-160(1)$} & \multicolumn{2}{|c|}{$161-170(5)$} & \multicolumn{2}{|c|}{$171-180(5)$} & \multicolumn{2}{|c|}{$211-220$ (1) } \\
\hline & $\begin{array}{l}\mathrm{Fe}- \\
\text { male }\end{array}$ & Male & $\begin{array}{l}\mathrm{Fe}- \\
\text { male }\end{array}$ & Male & $\begin{array}{l}\mathrm{Fe}- \\
\text { male }\end{array}$ & Male & $\begin{array}{l}\text { Fe- } \\
\text { male }\end{array}$ & Male & $\begin{array}{l}\mathrm{Fe}- \\
\text { male }\end{array}$ & Male & $\begin{array}{l}\mathrm{Fe}- \\
\text { male }\end{array}$ & Male & $\begin{array}{l}\text { Fe- } \\
\text { male }\end{array}$ & Male \\
\hline $20-30$ & - & - & - & - & - & - & - & - & - & - & - & - & - & - \\
\hline $31-40$ & - & - & - & - & - & 1 & - & - & - & - & 2 & - & - & - \\
\hline $41-50$ & - & - & - & - & 1 & 2 & - & - & 1 & 2 & 3 & - & - & - \\
\hline $51-60$ & 1 & - & - & - & - & - & 1 & - & 1 & - & - & - & - & - \\
\hline $61-70$ & 1 & - & 1 & - & - & - & - & - & - & 1 & - & - & 1 & - \\
\hline
\end{tabular}

Table-III. Systolic B.P in diabetes mellitus according to age and sex. 


\begin{tabular}{|c|c|c|c|c|c|c|}
\hline \multirow{2}{*}{ Age (yrs) } & \multicolumn{5}{|c|}{ Diastolic B.P (18) } \\
\cline { 2 - 7 } & \multicolumn{2}{|c|}{$\mathbf{8 0 - 9 0}(\mathbf{1})$} & \multicolumn{2}{c|}{$91-100$ (10) } & \multicolumn{2}{c|}{ 101-110 (7) } \\
\hline \multirow{2}{*}{$20-30$} & Female (1) & Male (0) & Female (7) & Male (3) & Female (4) & Male (3) \\
\hline $31-40$ & - & - & - & - & - & - \\
\hline $41-50$ & - & - & - & - & 2 & 1 \\
\hline $51-60$ & - & - & 5 & 2 & - & 2 \\
\hline $61-70$ & 1 & - & 1 & - & 1 & - \\
\hline
\end{tabular}

Table-IV. Diastolic B.P in diabetes mellitus according to age and sex

\begin{tabular}{|c|c|c|c|c|c|c|c|c|c|c|}
\hline \multirow{3}{*}{ Age (yrs) } & \multicolumn{10}{|c|}{ Systolic B.P } \\
\hline & \multicolumn{2}{|c|}{$131-140(3)$} & \multicolumn{2}{|c|}{$141-150(10)$} & \multicolumn{2}{|c|}{$151-160(7)$} & \multicolumn{2}{|c|}{$161-170(10)$} & \multicolumn{2}{|c|}{$171-180(3)$} \\
\hline & $\begin{array}{c}\text { Female } \\
\text { (2) }\end{array}$ & $\begin{array}{c}\text { Male } \\
\text { (1) }\end{array}$ & $\begin{array}{c}\text { Female } \\
\text { (5) }\end{array}$ & $\begin{array}{c}\text { Male } \\
\text { (5) }\end{array}$ & $\begin{array}{c}\text { Female } \\
(5)\end{array}$ & $\begin{array}{c}\text { Male } \\
(2)\end{array}$ & $\begin{array}{c}\text { Female } \\
(5)\end{array}$ & $\begin{array}{c}\text { Male } \\
(5)\end{array}$ & $\begin{array}{c}\text { Female } \\
\text { (1) }\end{array}$ & $\begin{array}{l}\text { Male } \\
\text { (2) }\end{array}$ \\
\hline $20-30$ & - & - & - & - & - & - & - & - & - & - \\
\hline $31-40$ & - & - & 1 & 3 & 1 & 1 & 1 & 4 & - & - \\
\hline $41-50$ & 1 & - & 2 & 1 & 3 & - & 2 & - & - & - \\
\hline $51-60$ & 1 & - & 2 & 1 & 1 & - & 1 & 1 & 1 & 2 \\
\hline $61-70$ & - & 1 & - & - & - & 1 & 1 & - & - & - \\
\hline
\end{tabular}

\begin{tabular}{|c|c|c|c|c|c|c|}
\hline \multirow{2}{*}{ Age (yrs) } & \multicolumn{6}{|c|}{ Diastolic B.P (33) } \\
\cline { 2 - 7 } & \multicolumn{2}{|c|}{$80-90(4)$} & \multicolumn{2}{c|}{$91-100$ (15) } & \multicolumn{2}{c|}{ 101-110 (14) } \\
\hline & Female (2) & Male (2) & Female (7) & Male (8) & Female (9) & Male (5) \\
\hline $20-30$ & - & - & - & - & - & 3 \\
\hline $31-40$ & - & - & 1 & 5 & - & - \\
\hline $41-50$ & - & 1 & 2 & - & 6 & 2 \\
\hline $51-60$ & 2 & - & 3 & 2 & 1 & - \\
\hline $61-70$ & - & 1 & 1 & 1 & - & 2 \\
\hline
\end{tabular}


The development of type 2 diabetes was almost 2.5 times as likely in persons with hypertension than in their normotensive counterparts. Moreover, each pathophysiological disease entity serves to exacerbate the other. The presence of hypertension in diabetic patients substantially increases the risks of coronary heart disease, stroke, nephropathy and retinopathy. Indeed, when hypertension coexists with diabetes, the risk of CVD is increased by $75 \%$, which further contributes to the overall morbidity and mortality of an already high-risk population.

Hypertension is one of the major factors contributing to atherosclerotic heart diseases. The patient should be labeled hypertensive ideally after recording of multiple readings on different occasions several weeks apart.

Prevention and control of hypertension and diabetes mellitus are essential as the life expectancy is increasing, the probability of chronic diseases will be on the rise especially in the elderly with co-existing morbidity. The main emphasis according to this study is on early detection of diabetes mellitus in hypertensive patients. Patients having increased blood pressure should check their blood sugar levels. The general population should also be encouraged to have their blood pressures monitored regularly after thirty years of age. Awareness among the population is needed to decrease the double burden on the society.

In one study, Essential Hypertension was screened for Impaired Glucose Tolerance (I.G.T.). All were aged between 30 to 64 years and had mild to moderate hypertension. None of them suffered from Diabetes Mellitus. Impaired Glucose Tolerance was found in $26 \%$, of cases. In our study it was $33 \%$. The prevalence was higher in those suffering from hypertension for a longer period of time. The results were compared with a control group of 50 subjects of similar age who were neither hypertensive nor diabetic. We had not used control group. Prevalence of Impaired Glucose Tolerance in this group was 6\%, I.G.T. is an important predictor of Type 2 Diabetes Mellitus ${ }^{11}$.

Recent epidemiological studies have demonstrated a strong positive correlation between systolic blood pressure and mortality, as well as between heart rate and mortality ${ }^{12,13}$. Impaired fasting glucose (prediabetes) and diabetes mellitus occur with increased frequency in hypertensive patients in a study, as in our study as well ${ }^{14}$.

In the context of elevated glucose, components of the metabolic syndrome appear to independently predict further hyperglycemia, but whether the syndrome predicts diabetes over and above its individual components is beyond the scope of this study.

Although the prevalence of diabetes increases with age, it remains unclear whether age is a risk factor for new-onset diabetes. In the a study, age at baseline was not an independent predictor of newonset diabetes.High-risk elderly hypertensive patients who did not have diabetes at baseline were survivors who had avoided the development of diabetes and that their underlying risk of new-onset diabetes and ability to metabolize glucose may thus have differed from those of younger subjects ${ }^{15}$. Our study show that diabetes and IFG increased with age (31-60 yrs) of age. However, it is also possible that the presence of other risk factors caused clinicians to test glucose more frequently among younger members, increasing the chance to identify diabetes standards of medical care for patients with diabetes mellitus.

In another study, we report changes in incidence rates of glucose intolerance over a 11-year period. In particular, differences between men and women were observed. The increased incidence of IGT in women compared with men, and increased 
incidence of IFG in men compared with women was consistent with, and explains the sex biases seen in the prevalences of these states ${ }^{16}$. We have nearly equal ratio. The total number of females are also increased.

In addition to the excess risk of hypertension, our data show that hypertension is associated with impaired fasting glucose. Both hypertension and diabetes mellitus are great burden to society. Our results suggest that with known history of hypertension impaired fasting glucose levels are significantly increased. Impaired fasting glucose is an important predictor of diabetes mellitus. Although new predictors are there like $\mathrm{HbA1c}$ but in remote areas where facilities are not available to check it, then it is possible to check fasting glucose levels. Tight blood pressure control in patients with hypertension and type 2 diabetes achieves a clinically important reduction in the risk of deaths related to diabetes, complications related to diabetes, progression of diabetic retinopathy, and deterioration in visual acuity.

\section{CONCLUSIONS}

Hypertension is associated with diabetes mellitus and impaired fasting glucose.

\section{Copyright@ 24 Dec, 2012.}

\section{REFERENCES}

1. August P. Initial treatment of hypertension. Nejm 2003; 348: 610-7.

2. Nakanishi N, Li W, Fukuda H, Takatorige T, Suzuki K, Takara K. Multiple risk factor clustering and risk of hypertension in Japanese male office workers. Ind Health 2003;41:327-31.

3. Basile JN, Lackland DT, Basile JM, Riehle JE, Egan BM. A statewide primary care approach to cardiovascular risk factor control in high-risk diabetic and nondiabetic patients with hypertension. J Clin Hypertension 2004;6:18-25.

4. Ghaffar A, Reddy KS, Singhi M. Burden of noncommunicable diseases in South Asia. BMJ 2004;
$328: 807-10$.

5. Nishtar S, Faruqui AMA, Mattu MA, Mohamud KB, Ahmed $A$. The National Action Plan for the prevention and control of non-communicable diseases and health promotion in Pakistan Cardiovascular Diseases. J Pak Med Assoc 2004;54(3 Suppl):S14-25.

6. Pakistan Medical Research Council. National Health Survey of Pakistan 1990-94. Islamabad 1998.

7. Assmann G, Cullen P, Schulte H. The Munster Heart Study (PROCAM): results of follow-up at 8 years. Eur Heart J 1998;83(19 suppl):2-11.

8. Sowers JR, Epstein M, Frolic ED. Diabetes hypertension, and cardiovascular disease. An update. Hypertension. 2001; 37:1053-9.

9. Gress TW, Nieto FJ, Shahar E. Hypertension and antihypertensive therapy as risk factors for type-2 diabetes mellitus. Atherosclerosis Risk in Communities Study. N Engl J Med 2000;342:905-12.

10. Dagogo-Jack S, Askari H, Tykodi G. Glucoregulatory physiology in subjects with low-normal, highnormal, or impaired fasting glucose. J Clin Endocrinol Metab 2009;94:2031-6.

11. Rahman F, Naseemullah M, Ahmed SI. Impaired glucose tolerance in patients with essential hypertension. J Rawal Med Coll 1999; 3(1-2): 8-10.

12. Staessen JA, Gasowski J, Wang JG, et al. Risks of untreated and treated isolated systolic hypertension in the elderly: metaanalysis of outcome trials. Lancet 2000; 355: 865-72.

13. Greenland P, Daviglus ML, Dyer AR. Resting heart rate is a risk factor for cardiovascular and noncardiovascular mortality: the Chicago Heart Association Detection Project in Industry. Am J Epidemiol 1999; 149: 853-62.

14. Cheng C, S J. Studdiford, James J. Diamond JJ, Falkner EB. Impaired fasting glucose in hypertensive patients. Am J Hypertens 2003;16: 242-3.

15. Yasuno S, Ueshima K, Oba K, Fujimoto A, Hirata M, Ogihara $T$, et al. Is Pulse Pressure a Predictor of 
New-Onset Diabetes in High-Risk Hypertensive Patients?: A subanalysis of the Candesartan Antihypertensive Survival Evaluation in Japan (CASE-J) trial. Diabetes Care 2010 May; 33:1122-7.

16. Söderberg S, Zimmet P, Tuomilehto J, de Courten M, Dowse GK, Chitson, et al. High incidence of type 2 diabetes and increasing conversion rates from impaired fasting glucose and impaired glucose tolerance to diabetes in Mauritius. J Intern Med. $2004 \mathrm{Jul} ; 256(1): 37-7$.

\section{AUTHOR (S):}

1. DR. SHAHANA ARSHI

MBBS, FCPS

Medical Officer

Pakistan Institute of Medical Sciences, Islamabad.

2. DR. FAKHRA NAHEED

3. DR. MAZHAR BADSHAH

4. Dr. Farah $\mathrm{Naz}$

5. Dr. Kamran Sardar

\section{Correspondence Address:}

Dr. Shahana Arshi

MBBS, FCPS

Medical Officer

Pakistan Institute of Medical Sciences, Islamabad.

drshahana2004@yahoo.com

\section{PREVIOUS RELATED STUDIES}

Anila Kazi, Munawar Alam Ansari, Nasim Karim, Mehar Ali. GINGIVAL HYPERPLASIA; DURING VERAPAMIL THERAPY IN HYPERTENSIVE PATIENTS (Original) Prof Med Jour 13(2) 231-236 Apr, May, Jun, 2006.

Muhammad Zakria, Khalid Amin, Israr Kafeel, Masood Javaid, Zafar Alam. PREVALENCE OF RETINOPATHY IN HYPERTENSIVE PATIENTS (Original) Prof Med Jour 11(3) 267-272 Jul, Aug, Sep, 2004.

Shakeel-ur-Rehman, Khalid Amin, Aamir Shoukat, Zafar Alam, Muhammad Zakira. STROKE IN HYPERTENSIVE PATIENTS; ACT SCAN BASED 100 CASE STUDY (Original) Prof Med Jour 11(4)374-379 Oct, Nov, Dec, 2004.

PROF-2160

Anila Kazi, Munawar Alam Ansari, Nasim Karim, Mehar Ali. GINGIVAL HYPERPLASIA; DURING VERAPAMIL THERAPY IN HYPERTENSIVE PATIENTS (Original) Prof Med Jour 13(2) 231-236 Apr, May, Jun, 2006.

Muhammad Zakria, Khalid Amin, Israr Kafeel, Masood Javaid, Zafar Alam. PREVALENCE OF RETINOPATHY IN HYPERTENSIVE PATIENTS (Original) Prof Med Jour 11(3) 267-272 Jul, Aug, Sep, 2004.

Shakeel-ur-Rehman, Khalid Amin, Aamir Shoukat, Zafar Alam, Muhammad Zakira. STROKE IN HYPERTENSIVE PATIENTS; ACT SCAN BASED 100 CASE STUDY (Original) Prof Med Jour 11(4)374-379 Oct, Nov, Dec, 2004.

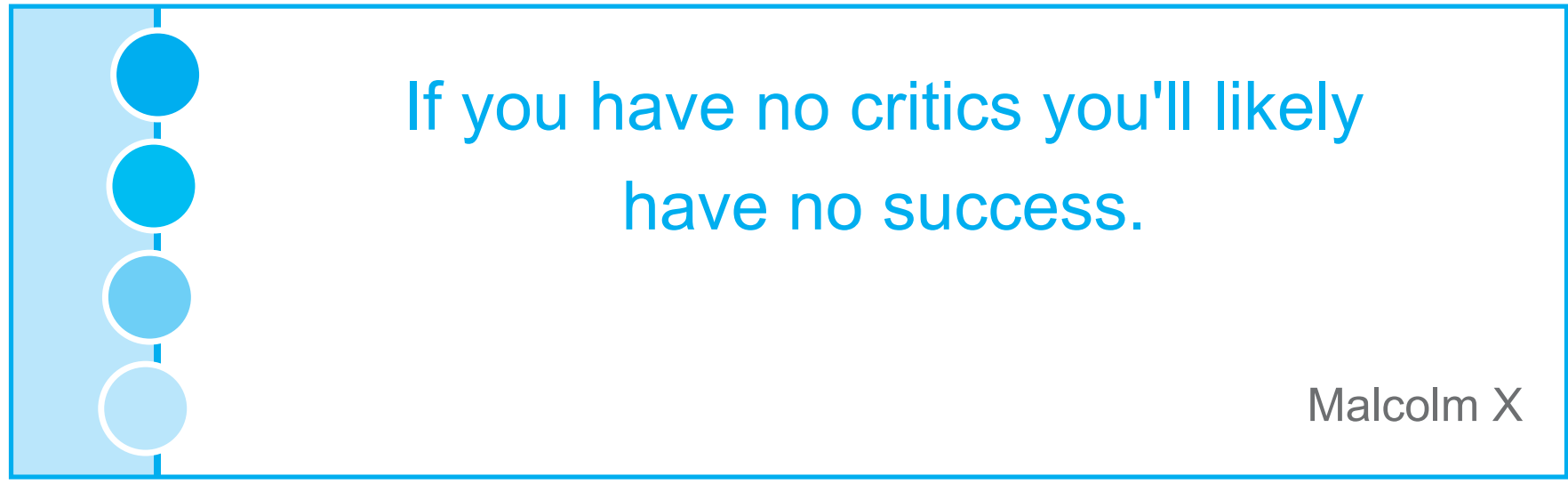

